\title{
Preventive role of chamomile flowers and fennel seeds extracts against liver injury and oxidative stress induced by an immunosuppressant drug in rats
}

\author{
Fathia A. Mannaa ${ }^{1}$, Nagi A. Ibrahim², Soliman S. Ibrahim², Khaled G. Abdel-Wahhab ${ }^{1}$, \\ Nabila S. Hassan ${ }^{3}$, Saida G. Mohammed²
}

${ }^{1}$ Department of Medical Physiology, National Research Centre, Dokki, Cairo 12622, Egypt

${ }^{2}$ Department of Zoology, Faculty of Science, Zagazig University, Zagazig 44519, Egypt

${ }^{3}$ Department of Pathology, National Research Center, Dokki, Cairo 12622, Egypt

\begin{abstract}
Aim: The present study was conducted to investigate the protective effect of chamomile flowers methanolic extract (CFME) and fennel seeds methanolic extract (FSME) on azathioprine (AZA), an immunosuppressant drug, which induced a liver injury and oxidative stress in rats. Methods: Rats were divided into 6 groups (8 rats each) and treated orally for 28 consecutive days as follows. Group 1: rats were given normal saline and used as controls; group 2: rats treated with CFME (200 mg/kg); group 3: rats treated with FSME (200 mg/kg); group 4: rats treated with AZA (25 mg/kg); and groups 5 and 6: rats treated with CFME $(200 \mathrm{mg} / \mathrm{kg})$ or FSME $(200 \mathrm{mg} / \mathrm{kg}) 15 \mathrm{~min}$ prior to AZA $(25 \mathrm{mg} / \mathrm{kg})$ treatment. At the end of experimental period, blood and liver samples were collected from all groups for biochemical analysis and histological examination. Results: The obtained data revealed that AZA-induced hepatic injury in the rats as evidenced by the significant increase in serum aspartate aminotransferase, alanine aminotransferase, alkaline phosphatase, cholesterol, and direct bilirubin as well as hepatic malondialdehyde level accompanied with significant decrease in reduced glutathione content and total antioxidant capacity in the liver. Moreover, body weight gain showed the significant decrease and relative liver weight showed the significant increase on AZA treatment. The sequential significant changes in biochemical parameters were accompanied by severe histological changes in the liver tissue, including hepatocytes disorganization with pyknotic nuclei, fatty degeneration, congestion, fibrosis, and bile duct necrosis around the portal tract. The areas of hemorrhages in blood vessels and in between hepatocytes were also seen. However, the results showed the potential hepatoprotective effects of CFME and FSME against AZA-induced liver injury and oxidative stress. They succeeded in restoring the biochemical parameters and improving the histological picture of the liver. This improvement was more pronounced in the rats pretreated with FSME. Conclusion: It could be concluded that CFME and FSME have hepatoprotective potentials against AZA probably due to their antioxidant properties and radical scavenging activity.
\end{abstract}

Key words: Azathioprine; chamomile flowers; fennel seeds; liver; oxidative stress

Address for correspondence:

Prof. Fathia A. Mannaa, Department of Medical Physiology, National Research Centre, Dokki, Cairo 12622, Egypt. E-mail: fathia_98@yahoo.com Received: 20-05-2015, Accepted: 21-09-2015

\begin{tabular}{|l|c|}
\hline \multicolumn{2}{|c|}{ Access this article online } \\
\hline \multirow{2}{*}{ Website: } & Quick Response Code \\
http://www.hrjournal.net/ & \\
& DOI: \\
10.4103/2394-5079.167375 & \\
&
\end{tabular}

This is an open access article distributed under the terms of the Creative Commons Attribution-NonCommercial-ShareAlike 3.0 License, which allows others to remix, tweak, and build upon the work non-commercially, as long as the author is credited and the new creations are licensed under the identical terms.

For reprints contact: reprints@ @medknow.com

How to cite this article: Mannaa FA, Ibrahim NA, Ibrahim SS, Abdel-Wahhab KG, Hassan NS, Mohammed SG. Preventive role of chamomile flowers and fennel seeds extracts against liver injury and oxidative stress induced by an immunosuppressant drug in rats. Hepatoma Res 2015;1:125-35. 


\section{INTRODUCTION}

Hepatotoxicants, including viruses, fungal products, bacterial metabolites, minerals, environmental pollutants, and chemotherapeutic agents, can induce various disorders of the organ ${ }^{[1]}$ Azathioprine (AZA) is a common immunosuppressant drug used in medicine to treat different diseases. ${ }^{[2]}$ It is now widely used in oncology, dermatology, gastroenterology, and rheumatology for its anti-leukemic and immunosuppressive properties. ${ }^{[3]}$ AZA (6-(1-methyl-4-nitroimidazol-5-yl) thiopurine) is also used for the prevention of rejection in organ transplants and the treatment of auto-immune diseases. ${ }^{[4]}$ It is indicated as an adjunct for the prevention of rejection in the renal transplantations. AZA is also used in the prevention of rejection in cardiac, hepatic, and pancreatic transplantations. ${ }^{[5,6]}$

The therapeutic use of AZA is associated with many complications. It induces a range of toxic effects that may ultimately result in the discontinuation of treatment. These toxic effects include gastrointestinal disturbances, pancreatitis, reversible alopecia, rashes, fever, tachycardia, pneumonitis, hypotension, and renal dysfunction..$^{[7]}$ Many studies have frequently reported the hepatotoxicity of AZA in vitro and in vivo. Many of these studies related the mechanism of hepatotoxicity and liver injury to the oxidative stress. AZA toxicity to rat hepatocytes in vitro and the mechanism of AZA toxicity to hepatocytes and decreasing its viability involves the depletion of glutathione (GSH) leading to mitochondrial injury with profound depletion of adenosine triphosphate (ATP) and cell death by necrosis were reported..$^{[8,9]}$

Plants rich in natural polyphenolic compounds were intensely studied in recent years due to their potent anticarcinogenic, antioxidant, and immunomodulatory properties. Chamomile (Matricaria recutita L.) is one of the most widely used medicinal plants in the world. Aqueous chamomile extract is used as herbal medicine, in the form of tea, demonstrated to possess anti-inflammatory and antioxidant properties. ${ }^{[10]}$ Chamomile preparations are commonly used for many human ailments such as hay fever, muscle spasms, menstrual disorders, insomnia, ulcers, wounds, gastrointestinal disorders, rheumatic pain, and hemorrhoids, ${ }^{[11]}$ and also used to treat anxiety, hysteria, nightmares, insomnia, and other sleep problems. ${ }^{\mid 12]}$ The useful effects of chamomile are related to the presence of several flavonoid constituents (the most abundant phenolic compounds in herbs), and the core structure consists of either flavone (apigenin and luteolin) or flavonol derivatives (quercetin and patuletin). These occur in various forms such as aglyco- mono- and di-glycosides and/or acyl-derivatives. Other principal components are essential oils such as terpenoids, $\alpha$-bisabolol and its oxides, and azulenes including chalmuzene and acetylene derivatives. ${ }^{|13|}$

Fennel (Foeniculum vulgare Mill.), a plant belonging to the family Apiaceae, has a long history of herbal uses. Fennel seeds are used as analgesic, carminative, anti-inflammatory, diuretic, and antispasmodic agents. ${ }^{[14]}$ The antioxidant potential and antimicrobial activity of fennel seed extracts and essential oil have been reported. ${ }^{[14,15]}$ Fennel seeds methanolic extract contains (FSMEs) high amount of polyphenols, including flavonoids as a major component of polyphenols, gallic acid, caffeic acid, ellagic acid, quercetin, and kaempferol. ${ }^{[16]}$ Trans-anethole, fenchone, estragole, 4-terpineol, sabinene, alpha-terpinene and monoterpene hydrocarbons (limonene) as the major compounds, were identified in the essential oil. ${ }^{[17]}$

The present study was undertaken to elucidate the ability of oral chamomile flowers methanolic extract (CFME) and FSME to alleviate the adverse effects of AZA on the liver through biochemical and histological examinations in albino rats.

\section{METHODS}

\section{Experimental animals}

Male albino rats (Sprague-Dawley strains) weighing 150-200 $\mathrm{g}$ were used in this study. They were obtained from the animal house of National Research Centre, Giza, Egypt and acclimatized for 1 week prior to the experiment. Animals were housed in stainless steel cages at room temperature $\left(20-25^{\circ} \mathrm{C}\right)$ and a photoperiod of $12 \mathrm{~h}$ light-dark cycle. Animals were allowed free standard laboratory diet and drinking tap water ad libitum. This experimental study was approved by review board of National Research Centre.

\section{Chemicals}

AZA B.P uncoated tablets $50 \mathrm{mg}$ manufactured by RPG Life Sciences Ltd., Ceat Mahal, 463, Dr. A B Road, Worli, Mumbai: 400 025, India. Methyl alcohol (98\%) was obtained from El-Nasr Pharmaceutical Chemicals Co., "ADWIC" (Egypt). Perchloric acid and trichloroacetic acid (extra pure 99\%) were manufactured by SISCO Research Laboratories PVT LTD (Mumbai, India). Thiobarbituric acid was purchased from MERCK (Darmstadt, Germany). Other solvents and chemicals used were either analar or of analytical grade unless otherwise specified. Plant materials: Dried chamomile (Matricaria chamomilla) flowers and dried fennel (F. vulgare) seeds were purchased from Abd El-Rahman Harraz (Bab El-Khalk Zone, Cairo, Egypt).

\section{Preparation and extraction of the plant materials}

Three samples of dried chamomile flowers and fennel seeds were ground. Eighty grams of each ground sample were 
transported into $1 \mathrm{~L}$ Erlenmeyer flasks, and then $800 \mathrm{~mL}$ of $80 \%$ methanol $(80: 20$, methanol:water, v/v) were added to the samples. Extraction was carried out using an orbital shaker at a room temperature for $8 \mathrm{~h}$, they were filtrated through filter paper (Whatman No. 1), the residue was re-extracted twice for complete extraction, and then, the combined extracts of every sample were evaporated at $45^{\circ} \mathrm{C}$, using a rotary vacuum evaporator (Rotavapor R-114 BÜCHI, Switzerland) and stored at $-4{ }^{\circ} \mathrm{C}$ until use..$^{[15]}$

\section{Animal grouping}

Sixty rats were divided into six groups (10 rats each) based on their body weight and treated daily for 28 consecutive days as follows. Group 1: rats were administered with normal saline by gastric intubation and served as control group; group 2 : rats received CFME at a dose of $200 \mathrm{mg} / \mathrm{kg}$ (dissolved in normal saline) by gastric intubation; ${ }^{[18]}$ group 3 : rats received FSME at a dose of $200 \mathrm{mg} / \mathrm{kg}$ (dissolved in normal saline) by gastric intubation; ${ }^{[19]}$ group 4: rats were orally administrated with AZA at a dose of $25 \mathrm{mg} / \mathrm{kg}$ (dissolved in normal saline) by gastric intubation; ${ }^{[20]}$ group 5: rats were orally administrated with CFME at a dose of $200 \mathrm{mg} / \mathrm{kg}$ followed by AZA, after $15 \mathrm{~min}$, at a dose of $25 \mathrm{mg} / \mathrm{kg}$ by gastric intubation; and group 6: rats were orally administrated with FSME at a dose of $200 \mathrm{mg} / \mathrm{kg}$ followed by AZA, after $15 \mathrm{~min}$, at a dose of $25 \mathrm{mg} / \mathrm{kg}$.

During the experiment, the animals were weighed twice every week. Body weight gain (BWG) of each control and respective treated rats was calculated with reference to the initial body weight recorded at the beginning of the experiment and the final body weight at the end of the experiment.

\section{Collection of blood samples}

At the end of the experimental period, animals were fasted overnight. They were slightly anesthetized with diethyl ether. Blood samples were withdrawn from the retro-orbital venous plexus into serum tubes and left to clot and then centrifuged at $3000 \mathrm{~g}$ for $15 \mathrm{~min}$ at $4{ }^{\circ} \mathrm{C}$ where the clear sera were separated for the determination of alanine aminotransferase (ALT), aspartate aminotransferase (AST), alkaline phosphatase (ALP) activities, and total cholesterol, triglycerides, and total- and direct-bilirubin levels.

\section{Tissue sampling}

At the end of blood collection, each animal was rapidly sacrificed, and the liver was dissected out and weighed then apart from its left lobe was immediately kept in $10 \%$ buffered formalin-saline solution for a later histopathological examination. Another part from the same lobe of the liver was washed with saline, dried, weighed, and homogenized in $50 \mathrm{mmol} / \mathrm{L}$ phosphate buffer (ice-cold) solution ( $\mathrm{pH} \mathrm{7.4)}$ to give $20 \%$ homogenate $(\mathrm{w} / \mathrm{v}){ }^{[21]}$ The homogenate was centrifuged at $3000 \mathrm{~g}$ for $20 \mathrm{~min}$. The supernatant was separated and stored at $-70{ }^{\circ} \mathrm{C}$ until the determination of the levels of malondialdehyde (MDA), total antioxidant capacity (TAC), and reduced GSH content. Furthermore, the relative liver weight of each animal was then calculated as follows: Relative organ weight $=$ (absolute organ weight $[\mathrm{g}]$ $\times 100) /($ body weight of rat on sacrifice day $[g]$ ).

\section{Analytical determinations}

Colorimetric determinations of serum AST and ALT activities were carried out using UV-160 1PC UV-visible spectrophotometer (Shimadzu, Japan) for reading the absorbance. The assay was performed according to the instruction manual of RANDOX reagent kits manufactured by RANDOX Laboratories Ltd. (Admore, Diamond road, Crumlin, Co., Antrim, UK BT29 4QY). Colorimetric determination of serum ALP activity was performed according to the instruction manual of Reactivos GPL kits manufactured by Reactivos GPL (Barcelona, Espana, Spain). Serum total- and direct- bilirubin levels, triglycerides, and total cholesterol levels were determined colorimetrically using UV-160 1PC UV-visible spectrophotometer for reading the absorbance. The assays were performed according to the instruction manual of Reactivos GPL kits manufactured by Reactivos GPL (Barcelona, Espana, Spain). MDA as an indirect index for lipid peroxidation was determined in liver, based on its reaction with thiobarbituric acid which forms a pink complex that can be measured photometrically. ${ }^{[22]}$ Colorimetric determination of hepatic GSH content and TAC were carried out using UV-160 1PC UV-visible spectrophotometer for reading the absorbance using Kits produced by Biodiagnostic Co., Egypt.

\section{Histopathological examination}

Pieces of the livers from rats of control and treated groups were fixed in $10 \%$ formalin saline for $24 \mathrm{~h}$. More washing in tap water overnight was followed by dehydration in graded alcohol, clearing in xylene for $20 \mathrm{~min}$, and embedding in paraffin wax. Transverse serial sections were then cut at $5 \mu \mathrm{m}$ thickness and mounted on albuminized slide. ${ }^{[23]}$ Sections were stained with hematoxylin and eosin and investigated by light microscopy.

\section{Statistical analysis}

The obtained data were subjected to one-way analysis of variance. The analysis was performed using Statistical Analysis System (SAS) program software; copyright (c) 1998 by SAS Institute Inc., Cary, NC, USA. Tukey test was used to evaluate the significance between the individual groups at $P<0.05 .^{[24]}$ The values in this study were expressed as a mean \pm standard error. 


\section{RESULTS}

AZA treatment resulted in a significant increase in hepatic MDA level concomitant with a significant decline in hepatic GSH content and TAC as compared to control rats [Figure 1]. However, the administration of either CFME or FSME alone revealed insignificant changes in the mentioned parameters when compared to control rats except in rats that received FSME where a significant increase in hepatic GSH was observed. Pre-administration with CFME or FSME significantly reversed the elevation in hepatic MDA level and also reversed the decrease in hepatic GSH content and TAC-induced by AZA treatment toward the normal values of the controls.

The selected and specialized serum markers of liver functions among the different groups are shown in Figures 2 and 3. It is clearly indicated that CFME or FSME had no effect on AST, ALT, and ALP activities as well as total- and direct-bilirubin levels when compared with the control group. The treatment of rats with AZA alone resulted in significant increases in AST, ALT, and ALP activities, direct-bilirubin levels and a non-significant increase in total-bilirubin level. However, the administration of CFME or FSME to rats succeeded significantly in preventing the AZA-induced changes in the above mentioned parameters. In addition, the more prominent preventive effect was observed in the group pre-treated with FSME.

In the present study, serum triglyceride level showed insignificant change among the different studied groups, but serum cholesterol level increased significantly in AZA-treated rats as compared with the control group. The animals those were administrated with CFME or FSME alone showed an insignificant change in serum cholesterol level as compared with the control group. The administration of CFME in combination with AZA offered little protection against AZA-induced changes in cholesterol level, whereas the administration of FSME to rats succeeded in ameliorating significantly the AZA-induced changes in the mentioned parameter [Figure 4].

AZA treatment resulted in a significant decrease in BWG (\%), when compared to control rats [Figure $5 \mathrm{a}$ ]. The administrated with CFME produced a non-significant decrease in BWG, but FSME administration caused a significant decrease in BWG when compared to control rats. Pre-treatment with CFME before AZA treatment did not ameliorate the decrease in BWG induced by AZA treatment, while as pre-administration with FSME before AZA treatment induced a significant increase in BWG when compared to the AZA-treated group.

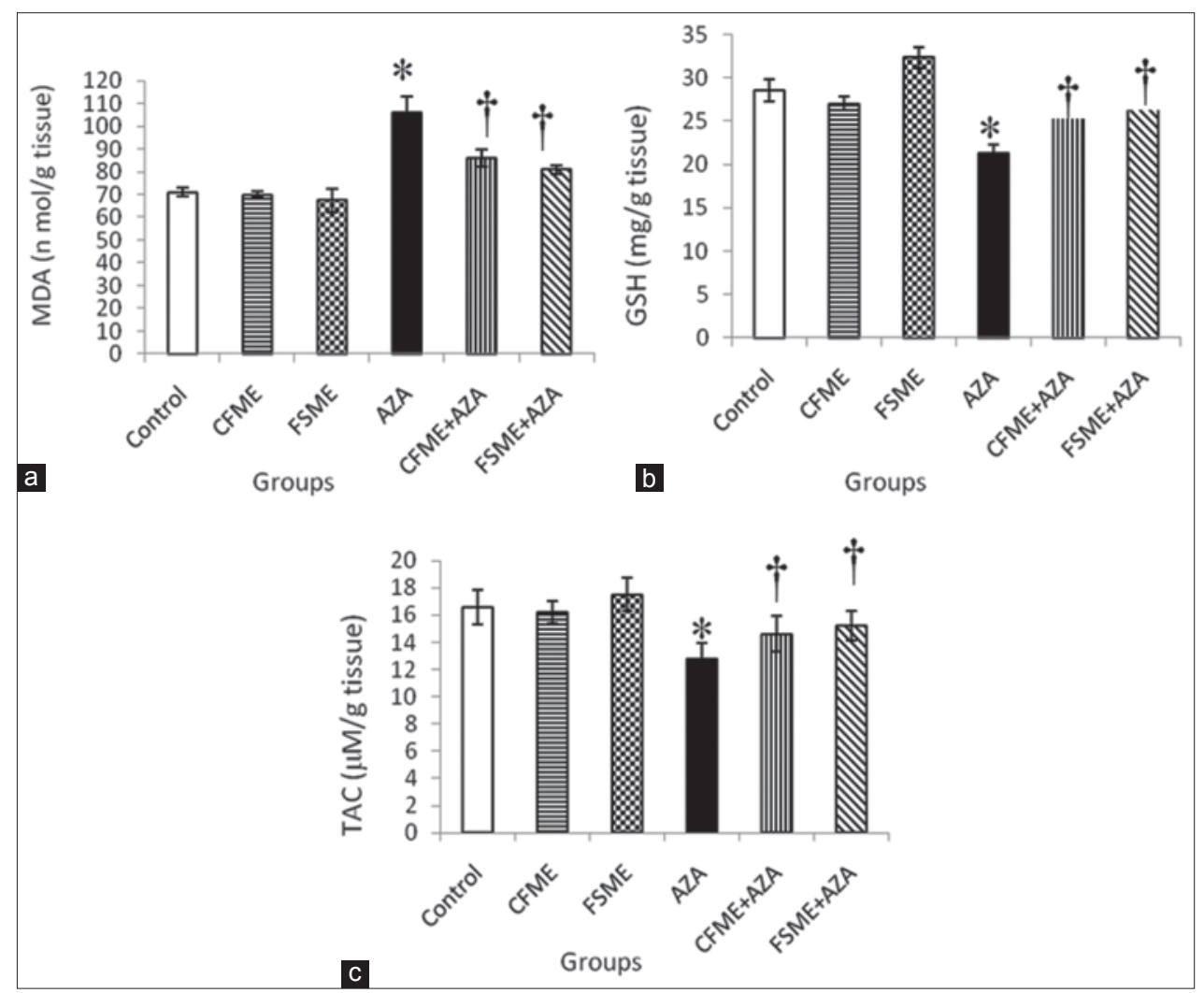

Figure 1: (a) Hepatic malondialdehyde (MDA) level; (b) hepatic reduced glutathione (GSH) level; and (c) total antioxidant capacity (TAC) in rats treated daily for 28 consecutive days with chamomile flowers methanolic extract (CFME), fennel seeds methanolic extract (FSME), azathioprine (AZA), CFME + AZA, and FSME + AZA. Data represent the mean \pm standard error $(n=8)$. ${ }^{*} P \leq 0.05$ compared to normal control rats; ${ }^{\dagger} P \leq 0.05$ compared to AZA-treated rats 
Data in Figure 5b show that AZA treatment induced a significant increase in mean relative liver weight (RLW) when compared to normal control rats. However, the oral administration of CFME or FSME did not significantly affect the mean RLW. The pre-treatment with CFME did not improve the increase in mean RLW ratio induced by AZA treatment, but the administration with FSME ameliorated the increase in mean RLW induced by AZA treatment.

The light microscopical examination of the liver sections from the control rats revealed normal hepatocytes architecture [Figure 6]. The liver sections obtained from FSME and CFME treated rats showed more or less normal hepatocytes architecture, but some congested blood vessels were seen in FSME-treated rats [Figure 7] and mild inflammation around the portal tract in the CFME-treated rats [Figure 8]. In contrast, the liver sections obtained from the AZA-treated rats revealed hepatocytes disorganization, and fatty degeneration as indicated by large and microvesicular fat droplets. The hepatocytes nuclei were shrinked and pyknotic or apoptotic. There were areas of hemorrhages in blood vessels and in between hepatocytes. Hepatocytes

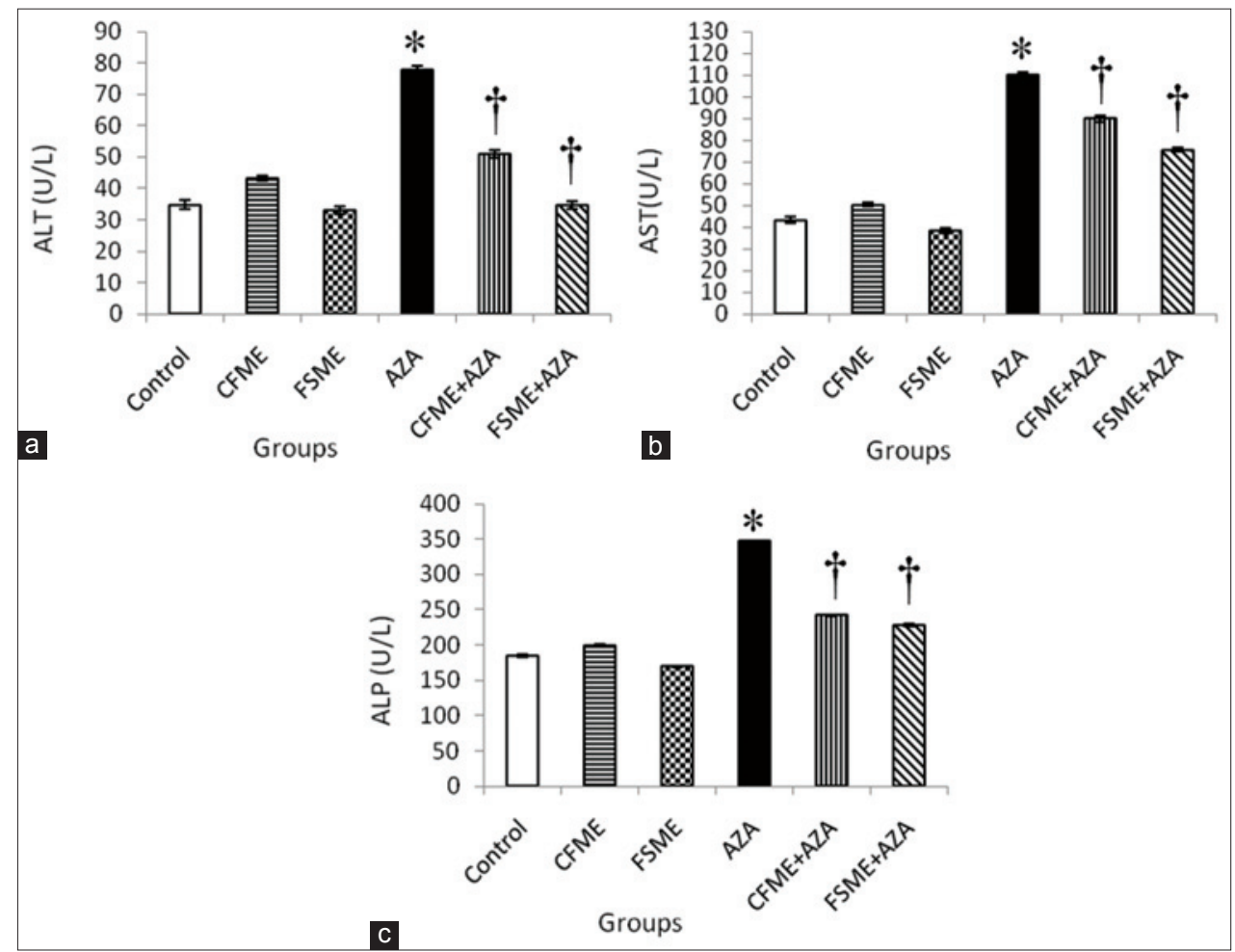

Figure 2: (a) Serum alanine aminotransferase (ALT) activity; (b) aspartate aminotransferase (AST) activity; (c) alkaline phosphatase (ALP) activity in rats treated daily for 28 consecutive days with chamomile flowers methanolic extract (CFME), fennel seeds methanolic extract (FSME), azathioprine (AZA), CFME + AZA, and FSME + AZA. Data represent the mean \pm standard error $(n=8) .{ }^{*} P \leq 0.05$ compared to normal control rats; ${ }^{\dagger} P \leq 0.05$ compared to AZA-treated rats

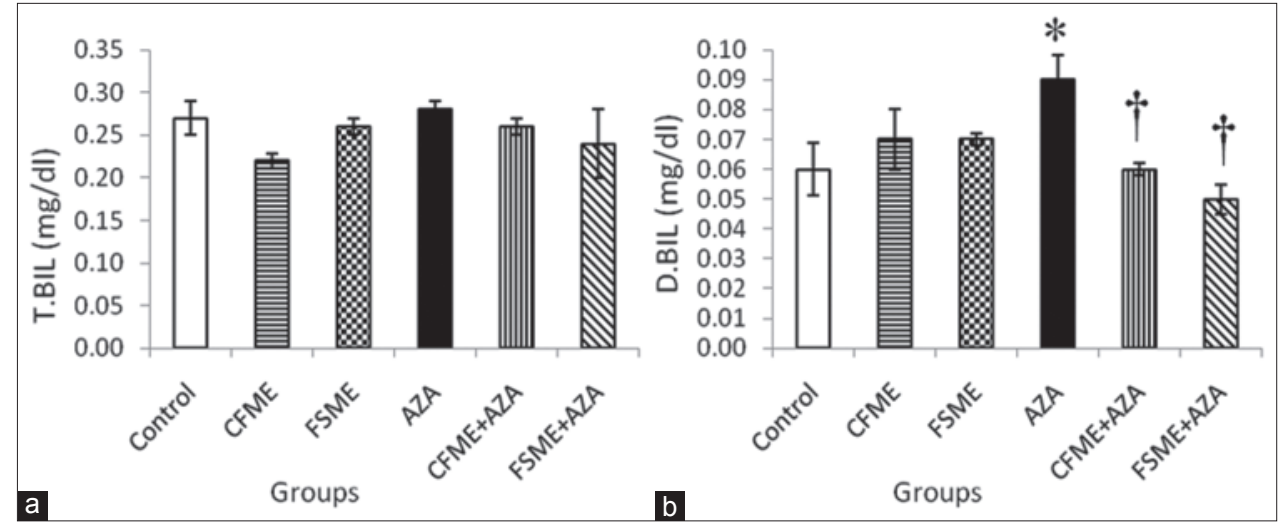

Figure 3: (a) Serum total-bilirubin (T.BIL) level; (b) direct-bilirubin (D.BIL) in rats treated daily for 28 consecutive days with chamomile flowers methanolic extract (CFME), fennel seeds methanolic extract (FSME), azathioprine (AZA), CFME + AZA, and FSME $+\mathrm{AZA}$. Data represent the mean \pm standard error $(n=8)$. ${ }^{\star} P \leq 0.05$ compared to normal control rats; ${ }^{\dagger} P \leq 0.05$ compared to AZA-treated rats 


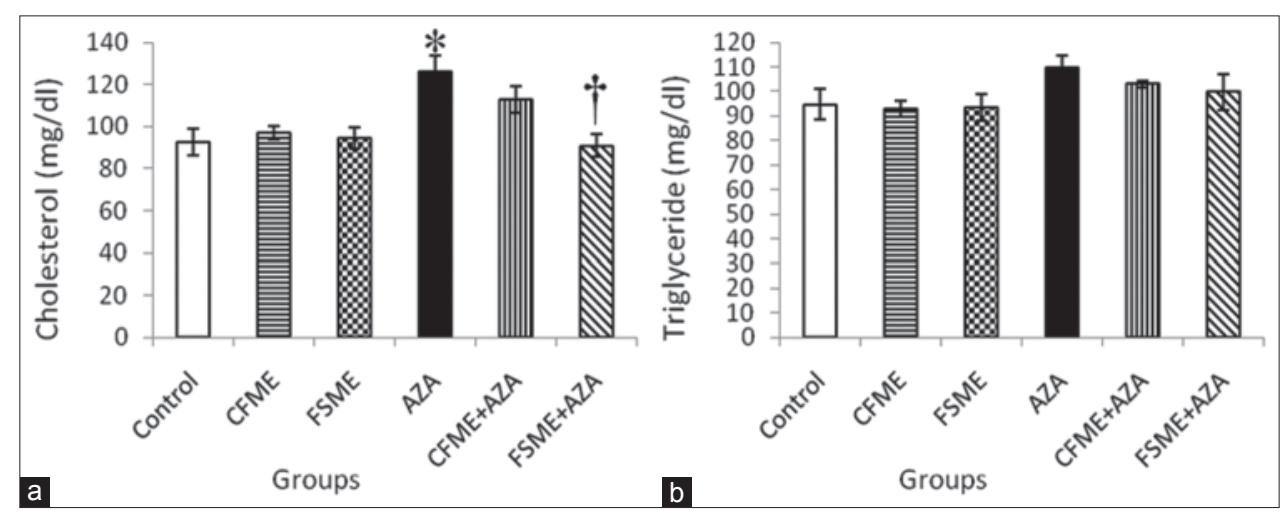

Figure 4: (a) Serum cholesterol; (b) triglyceride levels in rats treated daily for 28 consecutive days with chamomile flowers methanolic extract (CFME), fennel seeds methanolic extract (FSME), azathioprine (AZA), CFME + AZA, and FSME + AZA. Data represent the mean \pm standard error $(n=8)$. $P \leq 0.05$ compared to normal control rats; ${ }^{\dagger} P \leq 0.05$ compared to AZA-treated rats

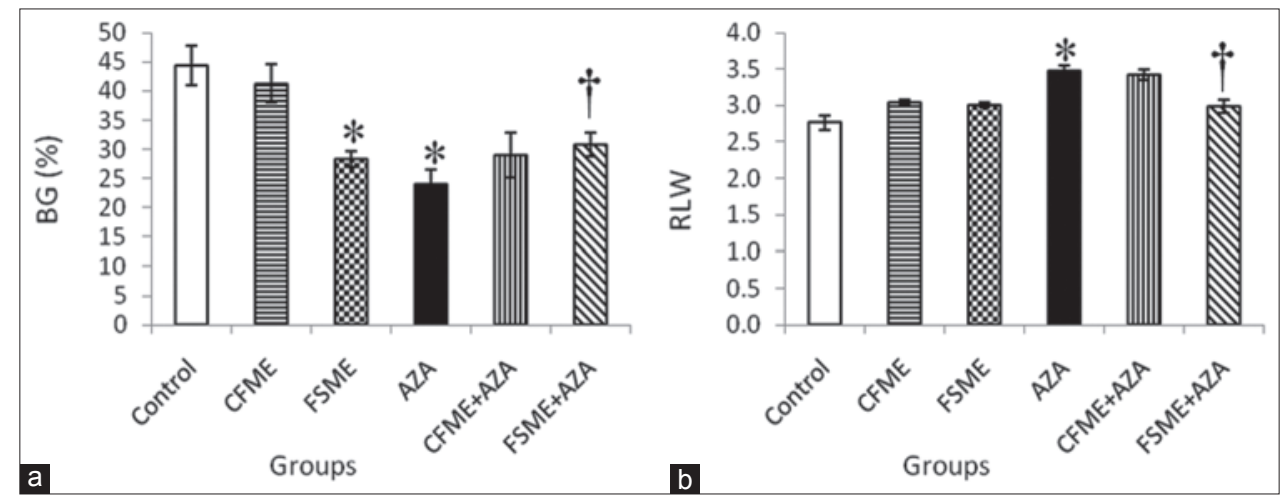

Figure 5: (a) Body weight gain (BG, \%); (b) relative liver weight (RLW) in rats treated daily for 28 consecutive days with chamomile flowers methanolic extract (CFME), fennel seeds methanolic extract (FSME), azathioprine (AZA), CFME $+\mathrm{AZA}$, and FSME $+\mathrm{AZA}$. Data represent the mean \pm standard error $(n=8)$. ${ }^{\star} P \leq 0.05$ compared to normal control rats; ${ }^{\dagger} P \leq 0.05$ compared to $A Z A$-treated rats

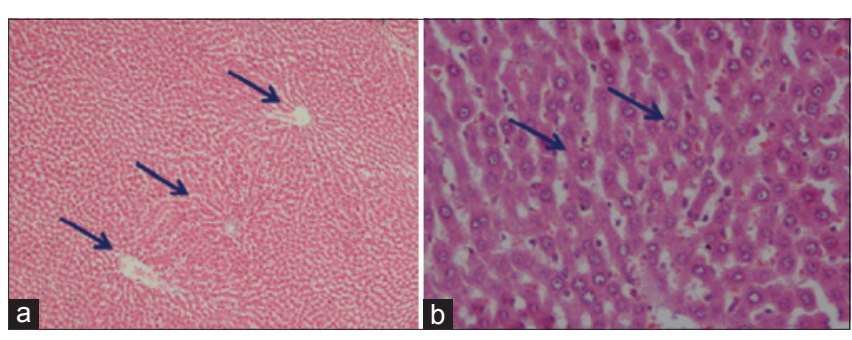

Figure 6: (a) Photomicrographs of liver sections of control rats showing the normal branching cords of hepatocytes around the portal tract and central vein separated by blood sinusoids ( $\mathrm{HE}, \times 100$ ); (b) high power of liver section of control rats showing the normal hepatocytes as polygonal cells having moderately acidophilic granular cytoplasm and rounded vesicular nuclei. Some cells are binucleated $(\mathrm{HE}, \times 400)$

were seen congested and fibrosed with pyknotic nuclei, microscpical examination also revealed bile duct necrosis around the portal tract [Figure 9]. The liver sections of rats treated with FSME prior to AZA treatment showed marked improvement and regeneration in the periportal and central zone. Some hepatocytes revealed acidophilic and granular cytoplasm with central rounded vesicular nuclei [Figure 10]. The liver sections of rats administrated with CFME prior to AZA treatment showed the normal hepatocytes architecture with normal central vein and portal tract, the fatty

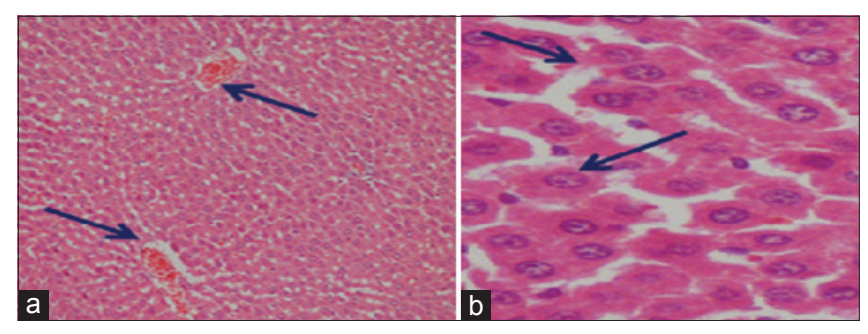

Figure 7: Photomicrographs of liver sections of fennel seeds methanolic extract treated rats showing the normal hepatocytes architecture $(a: H E, \times 100)$ and congested blood vessels (b: HE, $\times 400$ )

degeneration, and fibrosis or nuclear damage disappeared. Acidophilic cytoplasm with central rounded vesicular nuclei was observed [Figure 11].

\section{DISCUSSION}

AZA is a common immunosuppressant used in medicine to treat different diseases. ${ }^{[25]}$ However, AZA use has been complicated by a high incidence of hepatic injury which was found to be associated with oxidative damage. ${ }^{[26]}$ Hepatic injury is a common pathological feature which exists in many liver diseases. Liver fibrosis, cirrhosis, and even liver cancer 


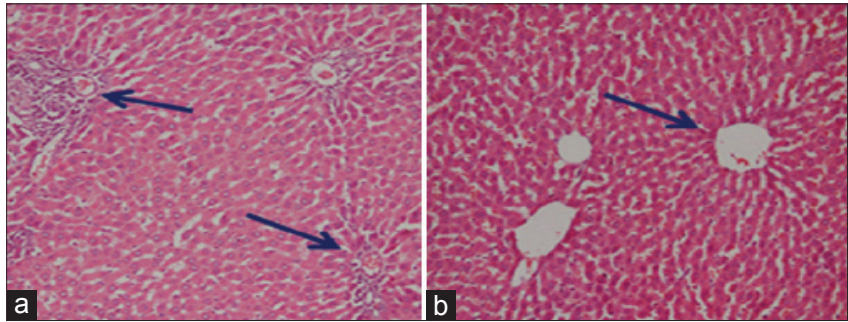

Figure 8: Photomicrographs of liver sections of chamomile flower methanolic extract treated rats showing the normal hepatocytes architecture in the central vein areas (a) and mild inflammation around the portal tract (b) (a and $b: \mathrm{HE}, \times 100$ )
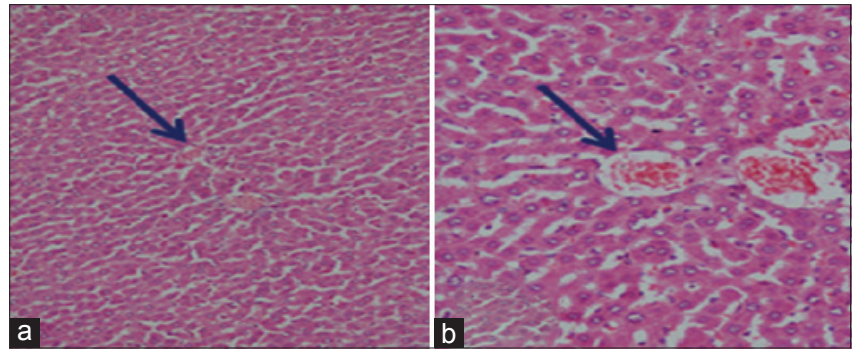

Figure 10: Photomicrographs of liver sections of fennel seed methanolic extract plus azathioprine treated rats showing the hepatocytes having acidophilic and granular cytoplasm with central rounded vesicular nuclei. Marked improvement and regeneration in the periportal $(\mathrm{a}: \mathrm{HE}, \times 100)$ and central zone $(\mathrm{b}: \mathrm{HE}, \times 300)$ are seen

could result from the long existence of hepatic injury. ${ }^{|27|}$ Chamomile flower and fennel seeds were reported to have antioxidant effects. Therefore, in this study, we investigated the protective effects of CFME and FSME, as natural products, against AZA-induced liver injury.

In recent years, there has been an increased interest in the possible role of reactive oxygen species (ROS) in the pathogenesis of tissue injury. ${ }^{[2]}$ Status of the oxidative/anti-oxidative profile was the mechanistic approach to assess the toxicity of AZA and/or protection to its toxic implications by using free radical scavengers ${ }^{\mid 28]}$ After administration, AZA is rapidly cleaved non-enzymatically within erythrocytes depending on GSH, ${ }^{[29]}$ to yield 6-mercaptopurine (6-MP) and an imidazole side chain. ${ }^{[30]} \mathrm{AZA}$ is also metabolized in the liver by the conversion of AZA to 6-MP catalyzed largely and enzymatically by GSH $S$-transferase ${ }^{[31]}$ using GSH as a substrate. ${ }^{[28]} \mathrm{AZA}$ metabolism in rat hepatocytes leads to GSH depletion, mitochondrial injury, decreased ATP levels, and cell death. ${ }^{[8]}$ 6-MP is further converted into 6-thiouric acid by xanthine oxidases (XO). It has been reported that $\mathrm{XO}$ has the potential to generate ROS in human hepatocytes ${ }^{[32]}$ and that the oxidation of 6-MP by $\mathrm{XO}$ is involved in the AZA-induced liver injury in patients with inflammatory bowel disease. ${ }^{[33]}$ Another metabolic pathway converts 6-MP into 6-thioinosine monophosphate via hypoxanthine-guanine phosphoribosyl transferase, and this intermediate is then metabolized into active 6-thioguanine

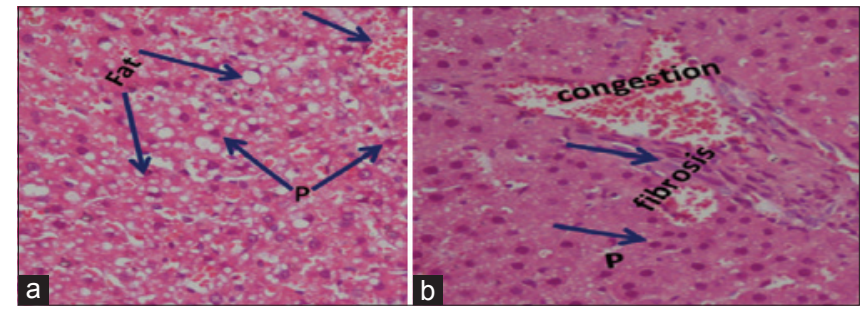

Figure 9: Photomicrographs of liver sections of azathioprine treated rats showing (a) hepatocytes disorganization, fatty degeneration indicated by large and microvesicular fat droplets. The hepatocytes nuclei are shrinked and pyknotic or apoptotic. Areas of hemorrhages in blood vessels and in between hepatocytes (HE, $\times 300$ ); (b) showing congestion, fibrosis and bile duct necrosis around the portal tract, the hepatocytes are disorganized with pyknotic nuclei $(\mathrm{P})(\mathrm{HE}, \times 400)$

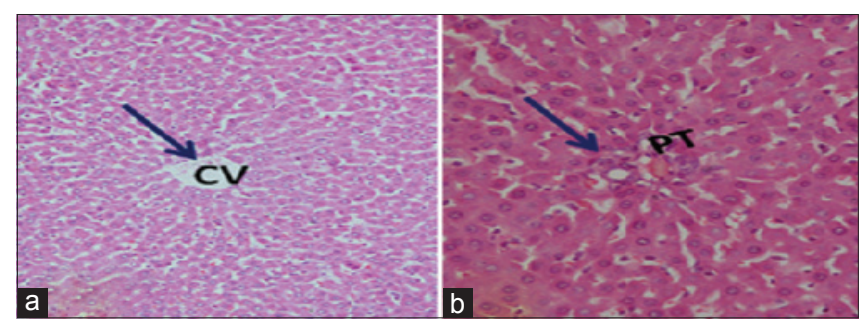

Figure 11: Photomicrographs of livers section of rats treated with chamomile flower extract prior to azathioprine treatment showing the normal hepatocytes architecture. The fatty degeneration and fibrosis or nuclear damage are disappeared and appearance of acidophilic cytoplasm with central rounded vesicular nuclei. Normal central vein $(\mathrm{CV})(\mathrm{a}: \mathrm{HE}, \times 100)$ and portal tract $(\mathrm{PT})(\mathrm{b}$ : $\mathrm{HE}, \times 300$ )

nucleotides (6-TGNs). ${ }^{[34]}$ 6-TGNs are also responsible for the cytotoxic side effects. ${ }^{[35]}$

The metabolic conversion of 6-MP into 6-thiouric acid via $\mathrm{XO}$, which is a critical source of ROS, potentially leads to hepatotoxicity. ${ }^{[32]}$ It has been suggested that ROS production by mitochondria caused by thiopurines could damage the membranes and macromolecules..$^{[8]}$ In the present study, the oxidative injury in AZA-treated animals was evident from the significant decline in GSH and TAC levels. The oxidative stress was further confirmed by increased lipid peroxidation and histopathological changes in the liver tissue. These findings are in agreement with previous studies, which recorded the involvement of oxidative stress and lipid peroxidation in AZA-induced liver injury. ${ }^{[32,36]}$

In hepatocytes, GSH is consumed during the metabolism of AZA to 6-MP. The mechanism of AZA toxicity to hepatocytes involves the depletion of GSH leading to mitochondrial injury with profound depletion of ATP and cell death by necrosis..$^{\mid{ }^{\mid 9}}$ Furthermore, GSH is responsible for ROS scavenging. Therefore, the decrease in GSH induced by AZA administration may be caused by the exhaustion of GSH during ROS scavenging. ${ }^{[32]}$ Lipid peroxidation, as well as altered levels of some endogenous scavengers, are taken 
as indirect in vivo reliable indices for the contribution of free radical generation and in turn oxidative stress. ${ }^{[37]}$ It has already been demonstrated that the depletion of GSH precedes the induction of lipid peroxidation. ${ }^{[38]}$

In this study, AZA-induced hepatotoxicity is evidenced by significant increments in the values of serum ALT, AST, ALP, direct-bilirubin, and cholesterol that may be attributed to the liver injury and also confirmed by pathological changes in the liver of AZA-treated rats. The increase of serum ALT, AST, and ALP activities may be mainly due to the leakage of these enzymes from the liver cytosol into the blood. ${ }^{[39]}$ In necrosis or membrane damage, ALT and AST are released into circulation, and it can, therefore, be measured in serum as markers of hepatic damage..$^{[40 \mid}$ Furthermore, our results are in agreement with a study which reported the cholestatic type of liver injury in a man treated with AZA, as developed after 16 days of starting AZA therapy. ${ }^{[41]}$

Serum ALP and total-bilirubin levels are also related to the status and function of hepatic cells. The increase in serum ALP is due to increased synthesis in the presence of biliary pressure. ${ }^{[42]}$ Bilirubin has been used to evaluate chemically-induced hepatic injury. It is one of the most useful clinical clues to the severity of necrosis, and its accumulation is a measure of binding, conjugation, and excretory capacity of hepatocytes. ${ }^{|43|}$

Lipids concentration is determined by metabolic functions, which are influenced by the integrity of vital organs such as the liver and kidney. Therefore, lipid profile such as cholesterol and triglycerides are increased in hepatopathy. The lipid content of hepatocytes is regulated by the integrated activities of cellular enzymes that catalyze lipid uptake, synthesis, oxidation, and export. ${ }^{[44]}$

In the current study, the observed decrease in BWG in rats treated with AZA are in agreement with the observations which reported the weight loss in rats ${ }^{[45]}$ and mouse ${ }^{[46]}$ exposed to cytotoxic agents such as AZA and methotrexate which could possibly be due to the inhibition of DNA synthesis and increased oxidative stress with consequent cellular damage of the body organs in affected rats..$^{[45]}$

Since oxidative stress has been recognized to be involved in etiology of several liver diseases and because liver is very susceptible to toxic effects, natural antioxidants, and plant extracts have been proposed as therapeutic agents to protect against liver damage ${ }^{[47 \mid}$ Administration of chamomile flowers and fennel seeds extracts to AZA-treated animals was potentially effective in reducing the lipid peroxidation and enhancing antioxidant capacity in the liver of AZA-treated animals. This appeared from the amelioration of MDA to near normal level and the significant improvement of the GSH and TAC contents. These results agree with that reported for chamomile flowers extract ${ }^{[48,49]}$ and for fennel seeds extract. ${ }^{[16,50]}$

In addition, chamomile flower and fennel seed extract could also significantly decrease serum ALT, AST, and ALP, suggesting their hepatoprotective activity. The mechanisms by which chamomile flower and fennel seed extracts offered their protective effects against AZA hepatotoxicity are based on their antioxidant abilities, which may be responsible for protecting the hepatic cells against the oxidative stress, possibly by increasing the endogenous defensive capacity of the liver to combat oxidative stress induced by AZA. This in turn improves the liver integrity and function and consequently improves the hepatic excretory function of bilirubin and also improves lipid metabolism. This improvement was more pronounced in the animals that were received fennel seed extract. Chamomile flower and fennel seed extracts also significantly ameliorated the decrease in the BWG. This may be attributed to the antioxidant effect of these extracts.

Several reports demonstrated that chamomile flowers and fennel seeds extracts contain important nutrients and exhibit antioxidant functions. The results of our recently published study revealed that the methanolic extract of both plants possesses considerable amounts of phenolic compounds and radical scavenging activity, ${ }^{[51]}$ which were in agreement with those reported recently. ${ }^{[52]}$ Some phenolic compounds have the capacity to quench lipid peroxidation products, prevent DNA oxidative damage, and scavenge ROS. ${ }^{|53|}$

Flavonoids isolated from chamomile, such as apigenin and luteolin, have been shown to possess antioxidant, anticarcinogenic, carminative, antispasmodic, and mild sedative properties. ${ }^{[54]}$ Fennel seed extract contains, by chromatographic analysis, trans-anethole, fenchone, methylchavicol, limonene, $\alpha$-pinene, camphene, $ß$-pinene, ßmyrcene, $\alpha$-phellandrene, 3-carene, camphor, and cisanethole. ${ }^{[55]}$ Among these, dlimonene and $ß$-myrcene have been shown to affect the liver function. D-limonene increases the concentration of reduced GSH in the liver. ${ }^{[56]}$

The biochemical investigations were confirmed by the histopathological results of the liver tissue. In our study, light microscopic examination of AZA-treated rats revealed hepatocytes disorganization, fatty degeneration indicated by large and microvesicular fat droplets and shrinkage, 
pyknotic, or apoptotic nuclei. Furthermore, large nodules with eosinophilic cytoplasm were present. Liver mean relative weight of AZA-treated rats was significantly increased as compared to control rats. These findings are in agreement with the findings of other investigators that reported an increase in mean relative liver weight in mice treated with AZA. ${ }^{[4]}$ In addition, disorganization of the liver architecture with multiple focal areas of necrosis in AZA-treated mice and other small hepatocytes with deeply stained acidophilic cytoplasm and dark nuclei were reported. ${ }^{[57]}$ Furthermore degenerated mitochondria, dilated cisterns of rough endoplasmic reticulum and multiple lipid droplets were noticed. A study reported that AZA-induced cell death (apoptosis), hydropic degeneration, portal fibrosis, and inflammation. ${ }^{[58]}$ It has been suggested that AZA induces hepatotoxicity and mitochondrial dysfunction owing to the stimulation of stress-activated protein kinase pathways and intracellular GSH reduction..$^{59]}$ On the other hand, the experimental evidence pointed to increased lipid peroxidation leading to the induction of a necrotic or apoptotic effect in hepatocytes. ${ }^{[8]}$ Furthermore, increase in ROS (as hydroxyl radical) could be involved in AZA toxicity. ${ }^{[32]}$

In contrast, mean relative liver weights were decreased in the rats treated with CFME or FSME before AZA treatment. Furthermore, marked improvements in the histopathological changes were noticed, due to their antioxidant abilities. Polyphenols and flavonoids in chamomile flowers extracts and apigenin-7-O-glucoside as the major constituent of chamomile which inhibited cancer cell growth were recorded. ${ }^{[60]}$ Al-Musa and Al-Hashem ${ }^{[49]}$ reported that the administration of ethanolic extract of chamomile flowers to streptozotocin-induced diabetic rats significantly ameliorated the morphological changes in the livers of treated rats. They attributed these effects to its potent antioxidant potential resulting in membrane stability. The increase in the antioxidant enzyme activity and the reduction in the lipid peroxidation by fennel methanolic extract may result in reducing a number of deleterious effects due to the accumulation of oxygen radicals, and could exert a beneficial action against pathological alterations, especially in inflammatory diseases. ${ }^{[19]}$

From the results of the current study, it can be concluded that oral administration of either CFME or FSME has a beneficial effect in modulating liver injury induced by AZA treatment probably through their potent antioxidative and radical scavenging activity and due to their higher content of total phenolic compounds. Both plants should be considered as accessible sources of natural hepatoprotective compounds.

\section{Financial support and sponsorship}

Nil.

\section{Conflict of interest}

There is no conflict of interest.

\section{REFERENCES}

1. Ha KT, Yoon SJ, Choi DY, Kim DW, Kim JK, Kim CH. Protective effect of Lycium chinense fruit on carbon tetrachloride induced hepatotoxicity. J Ethnopharmacol 2005;96:529-35.

2. $\mathrm{Xu} \mathrm{Z}$, Davis HM, Zhou H. Clinical impact of concomitant immunomodulators on biologic therapy: pharmacokinetics, immunogenicity, efficacy and safety. J Clin Pharmacol 2015;55:S60-74.

3. Lo LK, Hung CM, Chen YF, Ko WC, Tsai TF, Chu CY. Azathioprineinduced severe bone marrow toxicity - a report of 3 cases. Dermatol $\operatorname{Sin} 2009 ; 27: 44-51$.

4. Molyneux G, Gibson FM, Chen CM, Marway HK, McKeag S, Mifsud CV, Pilling AM, Whayman MJ, Turton JA. The haemotoxicity of azathioprine in repeat dose studies in the female CD-1 mouse. Int $J$ Exp Pathol 2008;89:138-58.

5. Nevins TE, Thomas W. Quantitative patterns of azathioprine adherence after renal transplantation. Transplantation 2009;87:711-8.

6. Heneghan MA, McFarlane IG. Current and novel immunosuppressive therapy for autoimmune hepatitis. Hepatology 2002;35:7-13.

7. Sweetman SC. Martindale: The Complete Drug Reference. 34th ed. London: Pharmaceutical Press; 2005.

8. Lee AU, Farrell GC. Mechanism of azathioprine-induced injury to hepatocytes: roles of glutathione depletion and mitochondrial injury. J Hepatol 2001;35:756-64.

9. Menor C, Fernández-Moreno MD, Fueyo JA, Escribano O, Olleros T, Arriaza E, Cara C, Lorusso M, Di Paola M, Román ID, Guijarro LG. Azathioprine acts upon rat hepatocyte mitochondria and stress-activated protein kinases leading to necrosis: protective role of N-acetyl-L-cysteine. J Pharmacol Exp Ther 2004;311:668-76.

10. Bhaskaran N, Srivastava JK, Shukla S, Gupta S. Chamomile confers protection against hydrogen peroxide-induced toxicity through activation of Nrf2-mediated defense response. Phytother Res 2013;27:118-25.

11. Srivastava JK, Shankar E, Gupta S. Chamomile: a herbal medicine of the past with bright future. Mol Med Rep 2010;3:895-901.

12. Martens D. Chamomile: the herb and the remedy. J Chiropr Acad Homeopath 1995;6:15-8.

13. Ganzera M, Schneider P, Stuppner H. Inhibitory effects of the essential oil of chamomile (Matricaria recutita) and its major constituents on human cytochrome P450 enzymes. Life Sci 2006;78:856-61.

14. Oktay M, Gülçin I, Küfrevioglu OI. Determination of in vitro antioxidant activity of fennel (Foeniculum vulgare) seed extracts. LWT Food Sci Technol 2003;36:263-71.

15. Anwar F, Ali M, Hussain AI, Shahid M. Antioxidant and antimicrobial activities of essential oil and extracts of fennel (Foeniculum vulgare Mill.) seeds from Pakistan. Flavour Fragr J 2009;24:170-6.

16. Mohamad RH, El-Bastawesy AM, Abdel-Monem MG, Noor AM, Al-Mehdar HA, Sharawy SM, El-Merzabani MM. Antioxidant and anticarcinogenic effects of methanolic extract and volatile oil of fennel seeds (Foeniculum vulgare). J Med Food 2011;14:986-1001.

17. Guillen MD, Manzanos MJ. A contribution to study Spanish wild-growing fennel (Foeniculum vulgare Mill.) as a source of flavour compounds. Chem Mikrobiol Technol Lebensmittel 1994;16:141-5.

18. Chandrashekhar VM, Ranpariyaa VL, Ganapaty S, Parashar A, Muchandi AA. Neuroprotective activity of Matricaria recutita Linn against global model of ischemia in rats. $J$ Ethnopharmacol 2010;127:645-51 
19. Choi EM, Hwang JK. Antiinflammatory, analgesic and antioxidant activities of the fruit of Foeniculum vulgare. Fitoterapia 2004;75:557-65.

20. Matsumoto K, Sekita K, Ochiai T, Takagi A, Takada K, Furuya T, Kurokawa Y, Saito Y, Teshima R, Suzuki K. Evaluation of immunotoxicity testings using azathioprine-treated rats: the international collaborative immunotoxicity study (Azathioprine). Eisei Shikenjo Hokoku 1990;108:34-9. (in Japanese).

21. Lin CC, Hsu YF, Lin TC, Hsu FL, Hsu HY. Antioxidant and hepatoproductive activity of punicalagin and punicalin on carbon tetrachloride induced liver damage in rats. J Pharmacol 1998;50:789-94.

22. Ruiz-Larnea MB, Leal AM, Liza M, Lacort M, de Groot H. Antioxidant effects of estradiol and 2-hydroxyestradiol on iron induced lipid peroxidation of rat liver microsome. Steriod 1994;59:383-8.

23. Drury RA, Wallington EA. Carleton's Histological Technique, 5th ed. New York: Oxford University Press; 1980. p. 206.

24. Steel RG, Torrie GH. Principles and Procedures of Statistics: A Biometrical Approach. New York: McGraw-Hill; 1980. p. 633.

25. Tabrizi BA, Mohajeri D, Mousavi G, Farajzada F, Khodadadi A, Alizae SB, Reihani B. Biochemical and pathological study of protective effect of Vitamin E in azathioprine-induced hepatotoxicity in rat. $J$ Biol Sci 2009;9:339-44.

26. El-Ashmawy IM, Gad SB, Salama OM. Grape seed extract prevents azathioprine toxicity in rats. Phytother Res 2010;24:1710-5.

27. Yuan HD, Jin GZ, Piao GC. Hepatoprotective effects of an active part from Artemisia sacrorum Ledeb. against acetaminophen-induced toxicity in mice. J Ethnopharmacol 2010;127:528-33.

28. Raza M, Ahmad M, Gado A, Al-Shabanah OA. A comparison of hepatoprotective activities of aminoguanidine and $\mathrm{N}$-acetylcysteine in rat against the toxic damage induced by azathioprine. Comp Biochem Physiol C Toxicol Pharmacol 2003;134:451-6.

29. Marino IR, Doyle HR. Conventional immunosuppressant drugs. In: Thomsom AW, Starzl TE, editors. Immunosuppressive Drugs: Developments in Anti-rejection Therapy. Boston: Little Brown; 1994. p. 5-7.

30. Elion GB. The purine path to chemotherapy. Science 1989;244:41-7.

31. Hobara N, Watanabe A. Impaired metabolism of azathioprine in carbon tetrachloride-injured rats. Hepatogastroenterology 1981;28:192-4.

32. Matsuo K, Sasaki E, Higuchi S, Takai S, Tsuneyama K, Fukami T, Nakajima M, Yokoi T. Involvement of oxidative stress and immune- and inflammation-related factors in azathioprine-induced liver injury. Toxicol Lett 2014;224:215-24.

33. Ansari A, Elliott T, Baburajan B, Mayhead P, O'Donohue J, Chocair P, Sanderson J, Duley J. Long-term outcome of using allopurinol co-therapy as a strategy for overcoming thiopurine hepatotoxicity in treating inflammatory bowel disease. Aliment Pharmacol Ther 2008;28:734-41.

34. Petit E, Langouet S, Akhdar H, Nicolas-Nicolaz C, Guillouzo A, Morel F. Differential toxic effects of azathioprine, 6-mercaptopurine and 6-thioguanineon human hepatocytes. Toxicol In Vitro 2008;22:632-42.

35. Armstrong VW, Oellerich M. New developments in the immunosuppressive drug monitoring of cyclosporine, tacrolimus, and azathioprine. Clin Biochem 2001;34:9-16.

36. Ahmed WM, Khalaf AA, Moselhy WA, Safwat GM. Royal jelly attenuates azathioprine induced toxicity in rats. Environ Toxicol Pharmacol 2014;37:431-7.

37. El-Khatib AS, Moustafa AM, Hamid AA, Al-Shabanah OA, El-Kashef HA. Effect of aminoguanidine and desferrioxamine on some vascular and biochemical changes associated with streptozotocin-induced hyperglycemia in rats. Pharmacol Res 2001;43:233-40.

38. Raza M, Al-Bekairi AM, Ageel AM, Qureshi S. Biochemical basis of sodium valproate hepatotoxicity and renal tubular disorder: time dependence of peroxidative injury. Pharmacol Res 1997;35:153-7.
39. Abdel-Wahhab MA, Hassan NS, El-Kady AA, Khadrawy YA, El-Nekeety AA, Mohamed SR, Sharaf HA, Mannaa FA. Red ginseng extract protects against aflatoxin B1 and fumonisins-induced hepatic pre-cancerous lesions in rats. Food Chem Toxicol 2010;48:733-42.

40. Oyagbemi AA, Odetola AA. Hepatoprotective effects of ethanolic extract of Cnidoscolus aconitifolius on paracetamol induced-hepatic damage in rats. Pak J Biol Sci 2010;13:164-9.

41. Choudhary NS, Gupta S, Chawla YK, Duseja A, Dhiman RK, Das A. Azathioprine induced liver injury: a case report. Dig Dis Sci 2012;57:1717-8.

42. Kumar RS, Manivannan R, Balasubramaniam A, Rajkapoor B. Antioxidant and hepatoprotective activity of ethanol extract of Indigofera trita Linn. on $\mathrm{CCl}_{4}$ induced hepatotoxicity in rats. J Pharmacol Toxicol 2008;3:344-50.

43. Naik RS, Mujumdar AM, Ghaskadbi S. Protection of liver cells from ethanol cytotoxicity by curcumin in liver slice culture in vitro. J Ethnopharmacol 2004;95:31-7.

44. Seki S, Kitada T, Sakaguchi H, Nakatani K, Wakasa K. Pathological significance of oxidative cellular damage in human alcoholic liver disease. Histopathology 2003;4:365-71.

45. Akinlolu AA, Akinola OB, Khobe P, Obasi K, Dada O. Azathioprine and methotrexate impaired the morphology and functions of the testes in adult wistar rats. J Morphol Sci 2014;31:75-81.

46. Wielenga MC, van Lidth de Jeude JF, Rosekrans SL, Levin AD, Schukking M, D’Haens GR, Heijmans J, Jansen M, Muncan V, van den Brink GR. Azathioprine does not reduce adenoma formation in a mouse model of sporadic intestinal tumorigenesis. World J Gastroenterol 2014;20:16683-9.

47. El-Beshbishy H. Lipoic acid attenuates DNA fragmentation, oxidative stress and liver injury induced by tamoxifen in rats. Asian J Tradit Med 2007;2:175-88.

48. Sebai H, Jabri M, Souli A, Rtibi K, Selmi S. Tebourbi O, El-Benna J, Sakly M. Antidiarrheal and antioxidant activities of chamomile (Matricaria recutita L.) decoction extract in rats. J Ethnopharmacol 2014;152:327-32.

49. Al-Musa H, Al-Hashem F. Hypoglycemic, hepato-renal and antioxidant potential effects of Chamomile recutita flowers ethanolic extract in streptozotocin-diabetic rats. Am J Pharmacol Toxicol 2014;9:1-12.

50. Celik I, Isik I. Determination of chemopreventive role of Foeniculum vulgare and Salvia officinalis infusion on trichloroacetic acid-induced increased serum marker enzymes lipid peroxidation and antioxidative defense systems in rats. Nat Prod Res 2008;22:66-75.

51. Ibrahim NA, Mannaa FA, Ibrahim SS, Abdel-Wahhab KG, Mohamed SG. Protective potential of chamomile flowers and fennel seeds extracts against hemo- and immuno-toxicity of azathioprine in male Sprague-Dawley rats. J Environ Immunol Toxicol 2015; Epub ahead of print.

52. Roby MH, Sarhan MA, Selim KA, Khalel KI. Antioxidant and antimicrobial activities of essential oil and extracts of fennel (Foeniculum vulgare L.) and chamomile (Matricaria chamomilla L.). Ind Crops Prod 2013;44:437-45.

53. Diaz P, Jeong SC, Lee S, Khoo C, Koyyalamudi SR. Antioxidant and anti-inflammatory activities of selected medicinal plants and fungi containing phenolic and flavonoid compounds. Chin Med 2012;7:26.

54. Mckay DL, Blumberg JB. A review of the bioactive and potential health benefits of chamomile tea (Matricaria recutita L.). Phytother Res 2006;20:519-30.

55. Simándi B, Deák A, Rónyani E, Yanxiang G, Veress T, Lemberkovics E, Then M, Sass-Kiss A, Vámos-Falusi Z. Supercritical carbon dioxide extraction and fractionation of fennel oil. J Agric Food Chem 1999;47:1635-40.

56. Reicks MM, Crankshaw D. Effects of D-limonene on hepatic microsomal monooxygenase activity and paracetamol-induced glutathione depletion in mouse. Xenobiotica 1993;23:809-19. 
57. El-Beshbishy HA, Tork OM, El-Bab MF, Autifi MA. Antioxidant and anti-apoptotic effects of green tea polyphenols against azathioprine-induced liver injury in rats. Pathophysiology 2011;18:125-35.

58. Ardeshiri R, Ghassemi F, Kargar H. Histological study of azathioprine effect on liver in insulin resistant rats. Adv Environ Biol 2012;6:2784-90.
59. Moustafa AM, Badria FA. Impact of L-arginine on azathioprine-induced chronic hepatotoxicity in mice: biochemical and ultrastructural study. Egypt J Histol 2010;33:407-18.

60. Srivastava JK, Gupta S. Extraction, characterization, stability and biological activity of flavonoids isolated from chamomile flowers. $\mathrm{Mol}$ Cell Pharmacol 2009;1:138. 